\title{
LOS RELIEVES LABRADOS PARA LAS SOBREPUERTAS DE LA GALERÍA PRINCIPAL DEL PALACIO REAL *
}

\author{
POR \\ MARÍA LUISA TÁRRAGA BALDÓ \\ Dpto. de H. del Arte CSIC
}

\begin{abstract}
In this work I have studied a series of carved reliefs for the pelmets of the Royal Palace in Madrid, today preserved at the Prado Museum and at the Royal Academy of San Fernando.

Several news are brougth forward that allow us to know about their authentic artists, the exact number of them; the different materials that have been used, the judgement and valuation that these reliefs deserved from Sabatini and other contemporary sculptors; false attributions are cleared and a lot of unknown details about their fulfillment is provided here.
\end{abstract}

La serie ornamental de los relieves o "medallas» para las sobrepuertas del Corredor principal del Palacio Real de Madrid se labraron coincidiendo con los años de mayor esplendor de la escultura cortesana del siglo xviII. Por el tiempo que duró su ejecución, es una labor que se desarrolló casi íntegramente durante el reinado de Fernando VI; de forma que se proyectaron coincidiendo aproximadamente con su llegada al trono, 1747; a partir de 1749 se inician los trámites para seleccionar el material en que habían de trabajarse. Se comienzan a labrar en 1753, prolongándose su ejecución hasta septiembre de 1760 , fecha en que se entregaron los últimos de la serie. Su eliminación se produjo una vez acaecido el fallecimiento del citado monarca. A partir de entonces, estos relieves formaron parte de la ornamentación que desapareció del Palacio en la operación de limpieza escultórica que emprendió el recién llegado monarca Carlos III. Si bien, una vez eliminados, se siguió trabajando en ellos, concretamente, en aquellos no concluidos, con idea de que pudiesen ser utilizados en cualquier otro edificio, lo cierto es que su destino fue, en general, acabar siendo depositados en los almacenes del Palacio. Decimos, en general, porque como más adelante veremos, he podido constatar que algunos de ellos sí debieron de utilizarse.

El número de relieves proyectados por el P. Sarmiento para las sobrepuertas fue once para cada uno de los lados de la Galería principal. Esta cifra tiene su justificación en los huecos de puertas que se abrían a la citada Galería, pero este número no se mantuvo hacia Mediodía, puesto que para esta zona se idearon un total de trece, ya que para la entrada a la Capilla se pretendía una mayor riqueza ornamental, dato que obliga a rectificar las noticias hasta ahora conocidas que igualaban en número los relieves previstos para los cuatro muros de la misma, al menos en el proyecto inicial.

* Este trabajo ha sido financiado por la CICYT como parte del Proyecto de Investigación SEC92-0488. 
Los motivos elegidos para labrarse en los relieves se fijan en razón de la orientación en la que debían situarse: Mediodía, Oriente, Poniente y Norte. Estas noticias fueron dadas a conocer por Lorente Junquera ${ }^{1}$, sin embargo, es necesario volver a recordar cuáles fueron los temas elegidos para las sobrepuertas: hacia Oriente se escogieron hechos militares, exactamente, grandes victorias o batallas famosas acaecidas en España a lo largo de la Historia. Con esta decoración escultórica, evidentemente, lo que se conseguiría era un marcado sentido triunfal. Para estas sobrepuertas fueron proyectados y labrados: La Batalla de Covadonga (fig. 1), La Victoria de las Navas de Tolosa (fig. 2), Batalla de Clavijo (fig. 3), La Toma de Toledo, Batalla o Victoria del Salado ${ }^{2}$, Toma de Sevilla, La toma y conquista de Granada, La Conquista de Méjico (fig. 15), Conquista del Cuzco, Destrucción de Numancia, y el Triunfo de los españoles contra los cartagineses en Sagunto (fig. 4). La naturaleza de las escenas a plasmar marcaron estéticamente los relieves de esta parte de la Galería, pues casi todos ellos presentan escenas de guerra y, generalmente, son los triunfos del ejército cristiano. La composición se plantea con criterios bastante uniformes, de forma que el centro de la escena se reserva para situar y resaltar al protagonista principal de la hazaña quien, generalmente armado, bien a pie o a caballo, como tal héroe de la representación, aparece acompañado de algunos otros guerreros de su ejército que enarbolan banderas o insignias victoriosas, mientras los vencidos yacen en el suelo aplastados por la caballería de los vencedores, mostrándonos torsos retorcidos, medio moribundos o en un combate cuerpo a cuerpo. Hay ligeras alusiones al paisaje o a la ciudad en la que se dio la batalla que suele representarse al fondo, con escaso relieve.

El P. Sarmiento, a quien debemos, concretamente, este proyecto decorativo, eligió para Poniente la representación de las Ciencias. El benedictino proponía que fuesen nueve mujeres en relieve las que representasen las nueve Ciencias elegidas: La Gramática (fig. 5), La Poesía (fig. 6), Música, Matemática, Metafísica y Dialéctica (fig. 7), La Filosofía (fig. 8), Teología (fig. 13), Medicina y Astronomía. Estas nueve medallas se debían completar con dos hechos famosos de Literatura debidos a españoles, exactamente: La impresión de la Biblia Regia de Arias Montano y la edición de la Biblia Complutense. Podemos observar, sin embargo, que no todos los escultores respetaron la propuesta del P. Sarmiento pero, aun así, apreciamos en ellos una composición que, en términos generales, les proporciona cierto aire de parentesco: suele colocarse una figura femenina u otro motivo entre dos grupos de personajes que, distribuidos a ambos lados de la medalla, enmarcan el motivo central.

Al Norte, orientación en la que se erige la Capilla del Palacio, se colocarían otros once relieves de temática religiosa, concretamente: el hecho histórico sagrado de los dos textos Paralipómenos tocantes a David y Salomón, Cristo enviando a Santiago a predicar a España, Nuestra Señora que desciende a Toledo para vestir la casulla a San Ildefonso, San Isidro Labrador y el ángel, San Dámaso Papa, dictando a San Jerónimo (fig. 9), El martirio de San Lorenzo, el de Santa Eulalia (fig. 10), el de San Vicente, La Aparición de Santa Leocadia, más el Primer Concilio de España, y el Tercer Concilio de Toledo (fig. 14). Sin duda, este es el grupo de relieves que reúne, a mi juicio, mayor variedad compositiva y belleza plástica.

Por último, para las sobrepuertas del lado Sur se eligieron motivos de carácter político, representando los órganos supremos del gobierno de la nación: Consejo de Castilla (fig. 11), Consejo de la Inquisición, Consejo de Guerra, de Hacienda (fig. 12), de Indias, de Órdenes, de Cruzada, de Mesta y el de Estado y Cortes. Además, se habían de esculpir en dos relieves las dos famosas promulgaciones de las Leyes españolas, un Concilio Nacional Toledano y la Promulgación de las Leyes de las Siete Partidas. El planteamiento, por lo general, estriba en representar un interior en el que se sitúan una serie de personajes casi siempre sentados en torno a una mesa, presidida en

\footnotetext{
1 Lorente Junquera, M.: «Los relieves marmóreos del Palacio Real de Madrid», Arte Español, 1955, pág. 58.

2 Reproducido por Leticia Azcue Brea en La escultura en la Real Academia, Real Academia de Bellas Artes de San Fernando, 1994, pág. 115.
} 

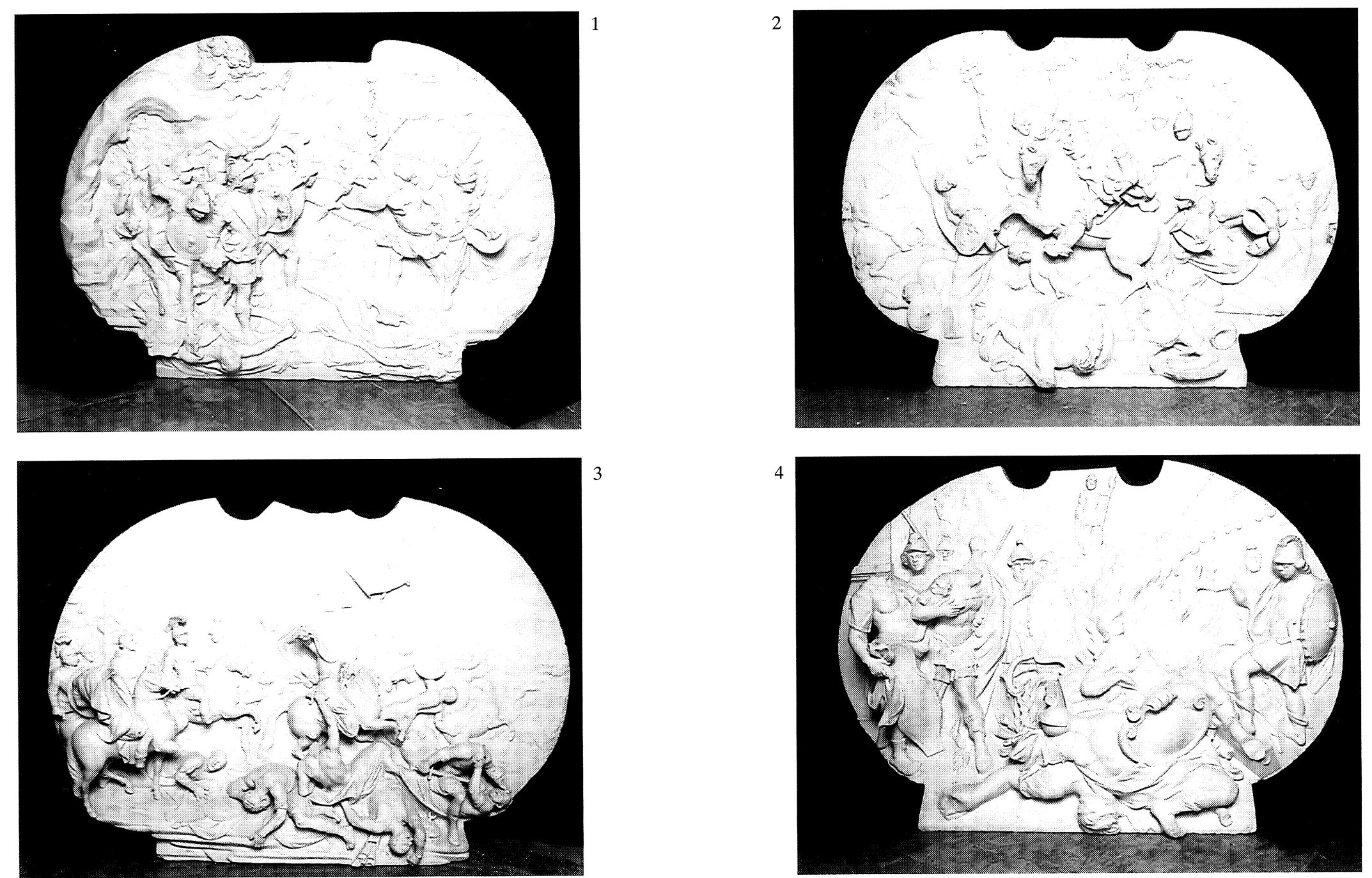

Fig. 1 y 2. Carlos Sala y Manuel Bergaz Batalla de Covadonga y Victoria de las Navas de Tolosa. Madrid. Museo del Prado. Fig. 3. Juan Porcel, Batalla de Clavijo. Madrid. Museo del Prado.

Fig. 4. Juan de Villanueva, Destrucción de Sagunto. Madrid. Museo del Prado. 
cada caso, según el Consejo de que se trate, por el mandatario correspondiente. En determinados casos, personajes alegóricos enmarcan la escena. Los fondos se resuelven con cortinajes, escudos o retratos reales. Según la valía del escultor al que se le encarga, se consigue representar no sólo con mayor acierto la perspectiva de ese interior sino mostrarnos una verdadera galería de retratos de Corte, como hace Manuel Álvarez en el Consejo de Guerra.

A pesar de lo que se ha venido repitiendo hasta ahora sobre cuál fue el número de los proyectados, repartidos y trabajados, hoy podemos asegurar que en total fueron cuarenta y seis las medallas proyectadas; pero ya antes de emprenderse el trabajo, según las fuentes documentales ${ }^{3}$ nos indican, sólo se precisaban treinta y siete, por la supresión, se dice, de la sobrepuerta de la Capilla; consta, sin embargo, que las distribuidas entre los escultores no fueron al final treinta y siete, sino treinta y nueve. Cuando se decide eliminar esta decoración y suspender este trabajo, se recogieron un total de treinta y seis entre las acabadas, a medio acabar o apenas desbastadas. Esta cifra puede originar algún equívoco, pero nuevamente la documentación nos aclara ${ }^{4}$ que de las quince últimas distribuidas sólo se lograron recoger doce de ellas, lo cual cuadra perfectamente con esas treinta y nueve que realmente se repartieron. Años más tarde, en 1789, al morir Carlos III, cuando se llevó a cabo el Inventario y tasación de la escultura de la colección real, Pedro Michel y Celedonio de Arce sólo mencionan en Palacio un total de treinta y dos ${ }^{5}$, número que abarca tanto los que allí había entonces acabados - veintiocho-, como los no concluidos - cuatro- y así quedó registrado en la Testamentaría del citado monarca, donde aparecen catalogados todos ellos con el n. ${ }^{\circ} 910$.

La serie, pues, había disminuido desde su entrega: de los treinta y nueve que inicialmente se habían distribuido, y de los treinta y seis recogidos al morir Fernando VI, ya faltaban en estas fechas, cuatro de ellos.

Posteriormente, cuando los relieves pasan desde el Palacio al Museo del Prado, en el Inventario del Museo donde se registran todos, exactamente, con el n. ${ }^{\circ} 738$ se dice: «Treinta y una medalla ovaladas de medio relieve de mármol de Carrara que representan diferentes asuntos, muchas de sus figuras están sin cabezas y sin extremos y una partida por medio en que se ve San Isidro, pertenecientes á la Galería principal de Palacio. Cuatro de ellas en desvaste. largo 4 pies y 3 pulgadas. Ancho 3 pies.» Es evidente que, de nuevo, de las treinta y dos tasadas e inventariadas a la muerte de Carlos III, no llegaron al Museo más que treinta y una. Por último, según publica Leticia Azcue ${ }^{6}$, el 18 de junio de 1934 la Academia acuerda solicitar del Patronato del Museo Nacional del Prado en concepto de depósito «seis medallones en mármol de la serie de los originales de antiguos pensionados de la Corporación que se conservan en el mencionado Museo..." para adornar las paredes del Salón de Actos, dejando en manos de D. Francisco Javier Sánchez Cantón, entonces Subdirector del Museo, la elección de los mismos. El Patronato del Museo decidió, por unanimidad, concederlos «sin menoscabo de la riqueza artística confiada a su custodia" "porque son obras que se hallan expuestas en sitios no visitados por el público» y así se le comunicaba a la Academia el 28 de julio del citado año 7 .

A través de la correspondencia mantenida entre la Academia y el Museo está claro que estos relieves eran considerados en aquellos años, equivocadamente, originales de los antiguos pensionados de la Academia de San Fernando, y procedentes de sus concursos.

3 De la Plaza, F. J.: El Palacio Real Nuevo de Madrid, Valladolid, 1975, pág. 182. Aquí se recoge como fuente documental el AGP, Secc. Ob., Leg. 355. Una noticia semejante y reproducción de las plantillas en M. L. Tárraga: Giovan Domenico Olivieri y el taller de escultura del Palacio Real, 1992, vol. III, doc. 204, págs. 846, 847 del AGP, Secc. Ob., Leg. 362.

4 AGP, Secc. Ob., Leg. 471.

5 Inventarios Reales. Carlos III, Madrid, Patrimonio Nacional, 1988, vol. I, pág. 93. Se dice textualmente: “Veinte y ocho Medallas concluidas de mármol de Badajoz $\mathrm{p}^{\mathrm{a}}$ la Galería de Palacio y quatro empezadas, las veinte y ocho a quince mil reales una con otra y las quatro a seis mil reales: suman todas... 444.000."

6 Azcue Brea, L., op. cit., pág. 149.

7 Ibídem. 

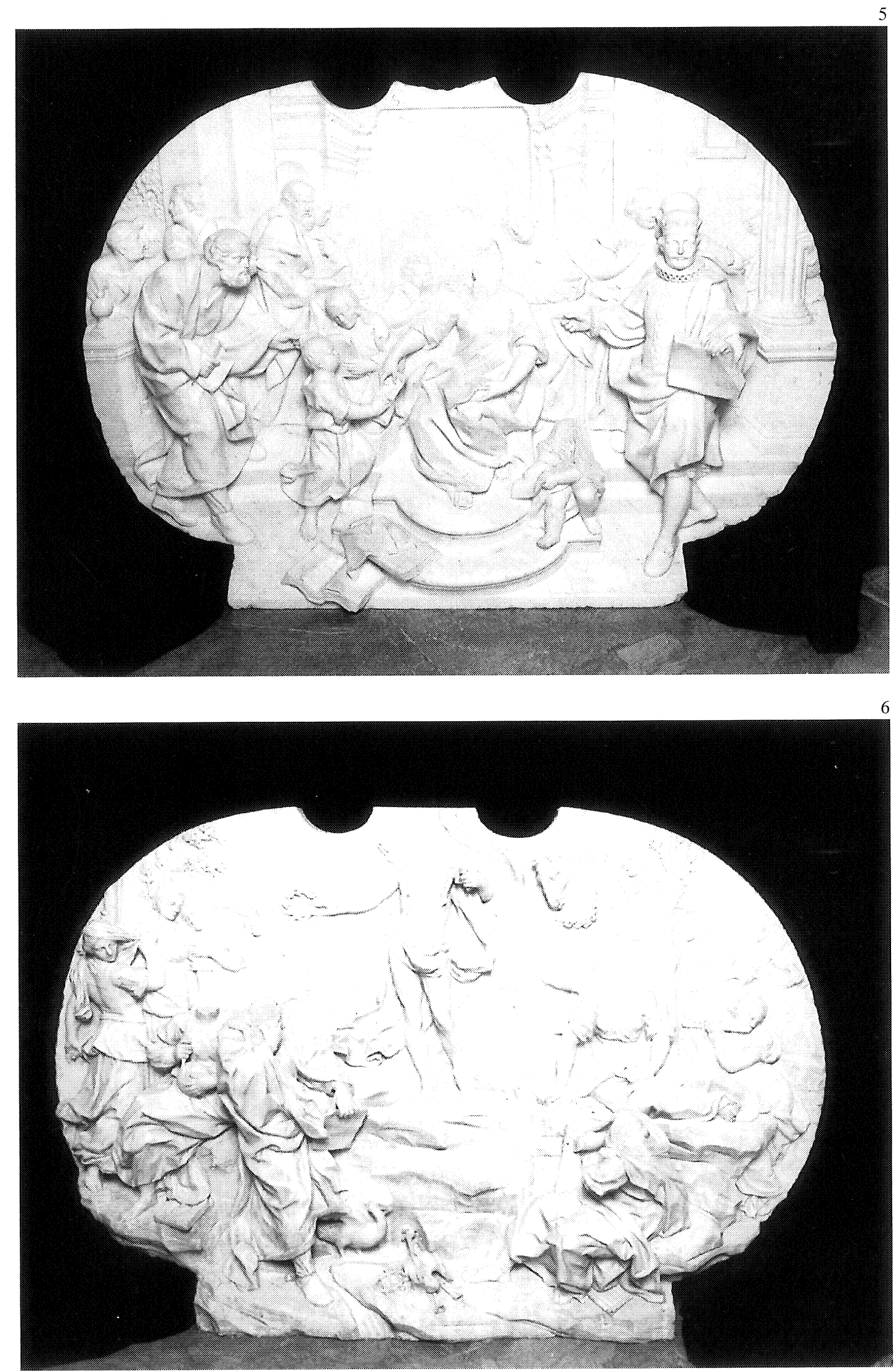

Fig. 5. Gregorio Carnicero, La Gramática. Madrid. Museo del Prado.

Fig. 6. Isidro Carnicero, La Poesía. Madrid. Museo del Prado. 
A partir de que Rocher Jorda ${ }^{8}$ se interesase y sintiese el deseo de averiguar la procedencia, autores y circunstancias en que llegaron al Museo del Prado los bajorrelieves que estudiamos, colocados entonces en la Galería de Poniente del Museo, y reprodujese alguno de ellos, exactamente cuatro, esta serie escultórica comenzó a despertar el interés y la atención posterior de otros investigadores, que sobre todo deseaban poder averiguar los interrogantes que los mismos planteaban.

Manuel Lorente Junquera ${ }^{9}$ lograba, gracias a la documentación que le facilitó Miss Eileen A. Lord, precisar cuál había sido su destino inicial y su procedencia, con anterioridad a su incorporación, en 1862, a la colección de esculturas del Museo del Prado. Asimismo, nos daba a conocer los nombres de aquellos escultores encargados de labrar un número importante de estos relieves, si bien, no deja de reconocer que, a excepción de unos pocos, en gran parte, le eran escultores desconocidos. Lorente Junquera desvelaba, no sin algunas dudas, la temática que había de representarse en ellos. Aclaraba, además, cuál fue la distribución prevista para los mismos en los cuatro lados del Corredor principal del Palacio Nuevo y algunas noticias sobre la entrega de varios de ellos entre 1754 y 1759. Por último, examinaba con cierto detenimiento los seis que se conservan en la Real Academia, los cuatro que entonces estaban colocados en el vestíbulo de la planta baja del Museo del Prado y los otros cuatro sobre los medalleros de la Sala LXXII del mismo Museo pero, de todos ellos, sólo se reprodujeron y examinaron entonces un total de catorce, aquellos que merecieron su mayor atención y fueron también casi los únicos que hasta ahora han sido reproducidos ${ }^{10}$. Del resto, o lo que es lo mismo, de los diecisiete relieves que entonces estaban expuestos en la Galería exterior del Prado, el citado autor elude estudiarlos, argumentando que: «son obras de menor importancia que las anteriormente descritas»" 11.

El estudio de Lorente Junquera fue posteriormente completado en otros aspectos por Plaza Santiago en su obra El Palacio Real Nuevo de Madrid ${ }^{12}$, al tratar la Galería del cuarto principal del Palacio. Plaza Santiago nos aporta datos y noticias que han permitido mejorar el conocimiento de estos relieves. Concretamente precisó y en ocasiones modificó, fechas dadas por Lorente Junquera: las referidas al inicio de esta decoración. Dio a conocer la orden de Carlos III para que se suspendiera esta ornamentación y se recogieran los mismos y publicó las cantidades con que Olivieri y Castro tasaron casi la totalidad de ellos, así como la suma que efectivamente recibió cada uno de los escultores en pago por su obra. A estas valoraciones, añadió el autor algunos de los juicios emitidos por ambos directores de escultura: Olivieri y Castro, pero estas apreciaciones, únicamente referidas a siete de ellos. Concretamente: Cristo enviando a Santiago a predicar a España, El Consejo de Indias, Martirio de San Lorenzo, La Matemática, Primer Concilio de España y La Toma de Toledo ${ }^{13}$. A juicio del autor, estos comentarios nos informaban "sobre el talento no excesivo de casi todos sus autores, poco conocidos» ${ }^{14}$. Eran muchos, pues, los que quedaron por conocer. En este estudio ninguno aparece reproducido.

8 Rocher Jorda, F. de P.: "Los bajos relieves de la galería de Poniente del Museo del Prado", Rev. Coleccionismo, 1919 , t. VII, págs. 152 y 187.

9 Lorente Junquera, M., op. cit.

10 J. L. Melendreras Gimeno en el artículo "El escultor Bergaz: su obra en Murcia y en el Museo del Prado", Boletín del Museo del Prado, 1986, n. ${ }^{\circ}$ 21, t. VII, reprodujo la Batalla de las Navas y la de Covadonga, aunque junto a Bergaz hace aparecer como coautor a Juan de Salas, siendo Carlos Salas el escultor que colabora en ambos relieves. Las de Carmona fueron reproducidas en las publicaciones que a este escultor han dedicado M. Concepción García Gainza y J. J. Martín González. También las dos de Olivieri fueron reproducidas en el vol. III de mi estudio dedicado a él y el taller de escultura del Palacio.

11 Lorente Junquera, M., Op. cit., pág. 65. De estos diecisiete sólo se detuvo en los dos relieves considerados ambos hasta ahora obra de Carmona: San Isidro y el ángel y El Papa San Dámaso y San Yerónimo.

12 De la Plaza, F. J., op. cit., pág. 180.

13 Ibidem. Apéndice Documental n. ${ }^{\circ}$ LXXXIX, págs. 410, 411.

14 Ibidem, pág. 183. 
Una interesante aportación por parte del citado autor fue la publicación de la tasación que Juan Pascual de Mena y Roberto Michel hicieron, con la intervención de Sabatini, el 19 de enero de 1761, de los doce relieves que se recogieron, cumpliendo órdenes de Carlos III, quien pedía que a su entrega se tasasen según en el estado en que estuviese el trabajo.

Las investigaciones que vengo realizando sobre la colección de esculturas del Museo del Prado, unido a la rica documentación que conserva el archivo del Palacio referida, concretamente, a esta decoración escultórica, me ha permitido poder esclarecer aspectos oscuros o hasta ahora ignorados sobre ellos y así completar, y en ocasiones modificar e incluso ampliar la información que de estas medallas teníamos hasta ahora: precisar el número de relieves labrados, desvelar, en algunos casos, los verdaderos autores de estos relieves hasta ahora indebidamente atribuidos y, en general, aportar nuevos datos referidos al material, tasaciones, escultores que los trabajaron y nuevos juicios de los dos directores de escultura, Olivieri y Castro, encargados de dirigirlos, corregirlos y tasarlos, y muy especialmente los emitidos por el escultor Felipe de Castro, quien examina con detenimiento y rigor varias de estas piezas, dejando a través de sus escritos el análisis pormenorizado de la obra, a la vez que manifiesta rasgos acusados de su personalidad.

El hecho de haber sido una ornamentación trabajada a lo largo de tantos años, era lógico que engendrara una amplia documentación, sobre todo, si pensamos cuántos trámites y papeles circularon en Palacio durante su construcción.

Ya en algunas publicaciones anteriores identifiqué y examiné dos de estos relieves, de los que hasta entonces nada se sabía ${ }^{15}$. Eran, concretamente, los dos sólo desbastados -no tres como se ha dicho ${ }^{16}-$, que habían sido encargados a Olivieri y que integraban ese grupo último recogidos sin concluir. Ambos relieves forman parte de esos "cuatro inacabados» que se citan tanto en la Testamentaría ya mencionada de Carlos III, como en el Inventario del Museo del Prado. También tuve ocasión de dar a conocer el parecer del arquitecto Sabatini sobre ellos y que queda reflejado en estas breves líneas del referido escrito: «... si continuano a lavorare da dieci o dodici basi rilievi di marmo, che avevano pensato di mettere sopra tutte le porte e finestre del Portico superiore del sud ${ }^{\circ}$ Palazzo; e sapendo io dall'altro canto, che li Padroni non anno intentione di mettere queste pupazzate nel sud ${ }^{\circ}$ Luogo... Questo sarebbe un dispendio abastanza grande per S. M...; che secondo anno pagato gli altri, secondo mi dicono, a raggione di 20 mila reali l'uno, ascenderebbe alla somma di circa 200 mila reali per cose che non averanno in rigore la valuta di 4 maravedís l'uno.... ${ }^{17}$. Motivo que, indudablemente, aun teniendo en cuenta los gustos del nuevo monarca Carlos III, debió ser decisivo para detener este trabajo y mandarlo recoger y almacenar no importando ni lo avanzado de la obra ni la suma invertida hasta entonces en ella.

A pesar del rechazo hacia la ornamentación escultórica del Palacio y de no gustar estas medallas para decorar el mismo, Carlos III ordenó la conclusión de todos aquellos que habían sido entregados sin acabar. Se prevé, según algunos documentos, su posible utilización en cualquier otro edificio ${ }^{18}$. Por ello se decidió que los dos escultores, Olivieri y Castro, que hasta entonces habían estado encargados de dirigirlos, los terminasen. Motivo que suscitó las quejas de ambos y, en especial, de Felipe de Castro, quien argumentaba al respecto lo siguiente: «... Parece que la obligación impuesta a los Directores de la escultura del nuevo Rl. Palacio, está reducida a reveer y corregir los modelos; celar la ejecución de los modelos aprobados; aprobar o reprobar las obras según su mérito, después de concluidas, y tasadas por la pericia que deben tener de su ver-

15 Tárraga, M. L.: Relaciones artísticas entre España y América. Tárraga, M. L.: G. D. Olivieri y el taller de escultura..., vol. III, págs. 369-378.

16 De la Plaza, F. J., ibidem, pág. 185.

17 Tárraga, M. L.: G. D. Olivieri..., vol. II. Apéndice Documental, doc. n. ${ }^{\circ}$ 158, pág. 485 del AGP, Secc. Ob., Leg. 443.

18 Tárraga, M. L., op. cit., vol. III, pág. 902. AGP, Secc. Ob., Leg. 3. 

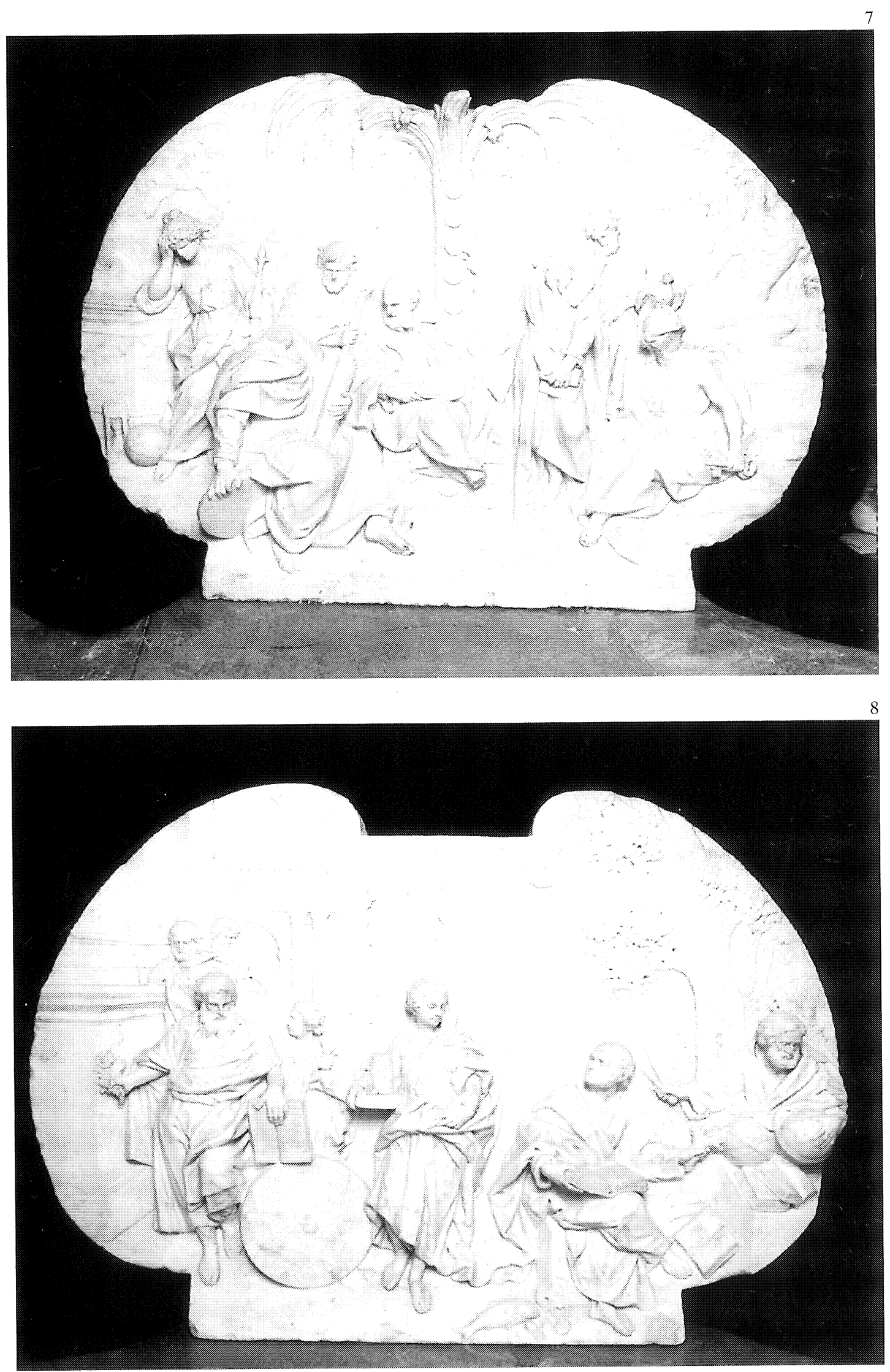

Fig. 7. Juan Martínez Reina, La Metafísica y la Dialéctica. Madrid. Museo del Prado. Fig. 8. Fernando Ortíz, La Filosofía. Madrid. Museo del Prado. 
dadero valor y ser por la confianza de sus empleos. Personas de toda integridad, para que no se admitan Obras imperfectas, ni pague más de lo justo... sin detenerme en exponer el inconveniente de que Yo concluya por mí las Medallas empezadas por mi subalternos, ó siga sus modelos, porque esto no es compatible debidamente hablando, con la fama que los primeros Profesores desean siempre conservar, inventando por sí los Modelos, y haciendo las obras originales, cuya fama necesariamente vendría a confundirse, si se viesen precisados a seguir las ideas de sus subalternos, pues aunque el mérito de éstos sea muy notorio y conocido conviene al honor y progreso de las Artes que cada Obra tenga Autor conocido, y que los defectos que uno pudiese cometer, no se atribuyan a Otro: O por el contrario, la perfección que puedan dar a la obra...." ${ }^{19}$. Se resistía Castro al mandato real, al igual que Olivieri, pero según sabemos la amenaza de retirarles el suelo, obligaría a ambos a su cumplimiento, aunque esta obediencia veremos en qué medida fue cumplida por ambos escultores.

La utilización de estas llamadas "medallas» en otro edificio, al menos como conjunto decorativo, que era una de las razones para que todos se concluyesen, se advierte, evidentemente, que no tuvo efecto, puesto que treinta y una de ellas pasaron al Prado.

Plaza Santiago, al plantearse cuál era el paradero actual de esta serie decorativa, no duda en aceptar y afirmar, apoyándose en las noticias facilitadas por Lorente Junquera, que veintiocho se instalaron en la galería exterior del Museo y seis pasaron a la Academia ${ }^{20}$; pero este número no concuerda con los treinta y uno que realmente ingresaron en el entonces Museo Nacional de Pintura y Escultura y que el propio Lorente Junquera recogió posteriormente en el Catálogo de la Escultura del Prado ${ }^{21}$.

El análisis detenido de los documentos permite apreciar que entre los entregados hasta 1760 y los que ingresaron en el Museo hay una diferencia numérica que nos obliga a concluir que al menos dos de ellos debieron cederse para ornamentación de algún otro edificio. ¿Cuál sea éste?, es una incógnita que está todavía por resolver. Plaza dio a conocer una carta del Cardenal Lorenzana, Primado de Toledo, solicitando en 1789 algunos de estos relieves "para decorar la capilla mozárabe» y que especialmente deseaba aquellos cuyo tema se relacionaba con la iglesia de Toledo, pero asegura Plaza: «los hechos prueban que el Cardenal no fue atendido», y añade: "Nada hay en la Capilla Mozárabe y en cambio los temas se encuentran entre lo que guarda el Prado y la Academia» 22. No reparó en que todos los relieves labrados no llegaron al Museo. Si esta petición no fue atendida, otras sí pudieron ser satisfechas, pues de las medallas que se dan como terminadas faltan dos y son exactamente: Cristo enviando a predicar a Santiago, la primera que se labró, cuyo autor fue el escultor portugués Antonio de Padua y La edición de la Biblia Regia Complutense y el rezo mozárabe, trabajada por el francés Francisco Devoge. Me atrevo a afirmar que las dos, debieron de donarse en vida de Carlos III y antes de que se realizase el inventario de sus bienes, puesto que ya en la Testamentaría apreciamos faltaban un número de ellas.

El inicio de estos relieves arranca de la primavera de 1749 con el planteamiento, previo a su ejecución, de resolver la elección del material en que habían de ser labrados; aunque Felipe V había decidido que en lo que respecta a la escultura para el interior y concretamente las partes decorativas que no fuesen las escaleras principales se había de trabajar en mármol de Badajoz o, en último extremo, Filabres, Fernando VI ordenaba el 26 de mayo de $1749{ }^{23}$ que, ante todo, los

\footnotetext{
19 Ibidem, vol. II, págs. 488-91. AGP, Secc. Ob., Leg. 471.

20 El hecho es que sólo llegaron al Museo del Prado treinta y uno y de ellos pasaron a la Academia los seis que allí se conservan.

21 De la Plaza, F. J., op. cit., pág. 187.

22 AGP, Secc. Ob., Leg. 26.

23 La orden dada al escultor F. de Castro tiene su justificación, puesto que Castro estaba entonces en las canteras de Colmenarejo dedicado a la búsqueda y selección de mármoles.
} 
escultores resolviesen si aparte de otras obras «los vajos reliebes Proyectados por el Padre Sarmiento, y aprobados por el Rey, para adornos de los Corredores..." se podían labrar usando el mármol blanco de Badajoz o el de Filabres en Granada, «que son los dos mejores que se han descubierto" y sobre todo para que quedasen con la perfección debida. En caso de que se pudiesen hacer de cualquiera de las dos clases de mármoles citados, se pedía que inmediatamente se hiciesen las plantillas para disponer la saca y conducción de la cantera que aprobaren. De lo contrario, se diría a los escultores que los mármoles para estas piezas se debían traer de Carrara. En tal caso, también los directores de escultura debían entregar las medidas y plantillas necesarias y una razón puntual de las calidades que querían los mármoles, dando opción Fernando VI, a través de su Ministro de Estado, Carvajal y Lancaster, a que los escultores indicasen incluso la cantera que preferían, si es que tuviesen conocimiento de alguna de calidad sobresaliente. Al mismo tiempo resolvía que, teniendo en cuenta la elección de mármoles para estos y otros trabajos escultóricos, Felipe de Castro "se retirase inmediatamente a Madrid» ${ }^{24}$. La misma orden preveía que del mármol de Carrara "sólo se ha de usar, después de haberse visto evidentemente que el mármol de Granada, y el de Badajoz, son inútiles para esta parte de obra.....

El parecer de los Directores de escultura debió de ser el aprobar el mármol de Badajoz. De forma que en la Junta de Gobierno de 18 de mayo de 1752 se da a conocer una carta del escultor Fernando Ruiz y Amaya enviado como responsable a las canteras de Extremadura para la saca y selección de mármoles, en que declara «tener hecho ya ajuste con José Antonio Foro, vecino de Cáceres para conducir 44 piedras que restaban de las 65 pequeñas que se le encargaron para adornos del Corredor sobre las Puertas del Quarto Principal, escaleras, y otros, en precio de 380 rs. cada pieza de las veinte y seis que estaban en Badajoz y de 340 rs. las diez y ocho restantes que otros conductores dejaron en Madridejo, jurisdicción de Trujillo, que por ser de poco peso pueden venir en Carretas, y este es, el tiempo de este carruage.... ${ }^{25}$. En ese mismo mes, tan sólo seis días después, Olivieri volvía a reconocer los huecos de la Galería en donde se debían poner las medallas encontrando, según dice, que eran 37 las sobrepuertas a decorar, al haberse suprimido las de la Capilla ${ }^{26}$. Pero, insisto, las repartidas finalmente fueron treinta y nueve. El 8 de julio de ese mismo año, 1752, los estatutarios pedían las piezas de mármol para hacer estas medallas, pero por entonces se habían suscitado ciertas dudas sobre la conveniencia de su colocación en las sobrepuertas alegando los facultativos que "quitan la luz a las piezas interiores" y por considerar «que la luz más alta está mejor» ${ }^{27}$ pero la Junta opinó era suficiente la claridad que quedaba y el suprimirlos suponía el trastocar el sistema de adornos del P. Sarmiento ya aprobado por el Rey. Es más, se piensa que «omitiéndose esta parte tan esencial se descompone su armonía..... Se pide entonces una determinación sobre la ejecución de las medallas y se añade que había ya en Madrid piedra para ellas, y los escultores no tenían trabajo.

La plantilla diseñada por Olivieri que se envía a Amaya tiene un perfil determinado, pero la realidad es que las medallas no son iguales en su contorno superior, habiendo dos tipos y en ocasiones hasta tres, tal y como muestran la reproducción de las propias medallas y que se corresponden con los perfiles que aún hoy podemos observar en los lugares en donde estas piezas debían colocarse.

Si bien consta la determinación de labrarlos en mármol de Badajoz, es fácil apreciar, en un examen directo, que no todos los relieves se labraron en esta calidad de material. Lorente Junquera ya señaló que no eran de mármol de Carrara, sino de Badajoz ${ }^{28}$. Posteriormente Plaza

24 AGP, Secc. Ob., Leg. 355.

25 AGP, Secc. Ob., Leg. 362.

26 AGP, Registro 572, f. 50.

27 Ibidem.

28 Lorente Junquera, M., ibídem, pág. 58. 
precisó que el relieve El Consejo de Castilla (fig. 11), labrado por Carnicero era mármol de Valencia ${ }^{29}$. Hoy podemos añadir que no fue éste el único trabajado en esta calidad de material, pues después de su observación directa y, según lo atestigua la documentación encontrada, la medalla que representa El Consejo de la Inquisición, en la Academia de San Fernando, realizada por Antonio Valeriano Moyano, es de piedra de Valencia. Cuando el 14 de mayo de 1753 por orden del Ministro Carvajal se reparten cinco relieves con destino a la pared del Mediodía entre aquellos escultores que no tenían trabajo, al hacer su distribución se expresa: el tema que han de labrar, el escultor a quien se le adjudica y la calidad de la piedra en la que han de trabajar; de forma, que claramente se señala: «... La Medalla que representa el Consejo de Castilla, se dé al escultor Carnicero; y la ha de hacer en una de las Piedras trahidas de Valencia. La que representa el Consejo de Inquisición se dé al escultor Dn. Antonio Moiano; y la ha de hazer en la Piedra de Valencia compañera que son dos. La que representa el Consejo de Guerra se de al escultor Alvarez, y la ha de hazer en Piedra de Badajoz. La que representa el Consejo de Hacienda se de al Escultor Bostón que la ha de hacer en Piedra de Badajoz. La que representa el Consejo de Indias, se de al Escultor Antonio de Padua, que la há de hazer en Piedra de Badajoz....” 30.

Castro, lo mismo que Olivieri, reconocieron esta piedra y aseguraban que era "un alabrastro o yeso de muy mala calidad, lleno de pelos y granos que no permiten poder perfeccionar en ella cosa de mediana consecuencia». Es más, Olivieri añade: «Y aunque Dn. Alejandro Carnicero aya podido reducir la Medalla que está aziendo, quasi a su entera conclusión es porque a escogido el pedazo menos malo que avia, ni por esto se deja de conocer no la podrá concluyr como quisiera y debiera, por ser la piedra mala; y que della está lleno el Reyno" ${ }^{31}$. Tales piedras habían sido traídas por José de Hermosilla, no sin suscitar las críticas de los escultores y hasta del propio Saqueti, quien consideraba que el joven Hermosilla carecía de los conocimientos precisos y había despilfarrado el dinero.

El 19 de agosto de 1758, un escrito de Olivieri a Elgueta pone de manifiesto la satisfacción del escultor italiano por los resultados conseguidos empleando el mármol de Badajoz en que se habían trabajado la mayoría. Decía al respecto: «de las medallas no tengo que decir nada porque han salido con un blanco muy hermoso, y sin manchas considerables. Las demás piezas en bruto prometen, no saldrán inferiores....) ${ }^{32}$.

Otro punto conviene aclarar: quiénes son los verdaderos autores de algunos de estos relieves, pues se han venido repitiendo como autores los nombres de determinados escultores, pero la documentación manejada obliga a correcciones y precisiones en este punto. En primer lugar, el relieve inacabado El Concilio III de Toledo en el Museo del Prado (fig. 14), que Lorente catalogó como Un Concilio sin dar nombre de su autor y Plaza lo consideró del escultor Juan de León, es obra que corresponde al escultor Francisco del Otero o Francisco Matías del Otero. Cuando se hizo la distribución se adjudicó al artista aragonés, pero las noticias de archivo desvelan que el 9 de abril de 1761, este desconocido escultor dirigía al Intendente del Palacio la siguiente súplica; «Francisco Ottero Profesor en el Arte de Escultura con el mayor respeto a V.S. digo, que en la instancia judicial que sigue a Dn. Juan de León por el trabajo que tengo hecho en la medalla de piedra, que se entregó sin acabar, en la que me tiene ya confesado haber sido todo este trabajo, y el Modelo de mi $\mathrm{qt}^{\mathrm{a}}$. Se me ha pedido el que yo saque de V. S. o con su orden, una Certificación de las Tasas y arreglo que los tasadores que fueron nombrados para su pago le hicieron, porque conviene asi para hacerle cargo al dho Dn. Juan de lo que a mi me corresponde

\footnotetext{
29 De la Plaza, F. J., ibídem, pág. 182.

30 AGP, Secc. Ob., Leg. 5.

31 AGP, Secc. Ob., Leg. 463, doc. n. ${ }^{\circ} 355$, pág. 646, vol. II. G. D. Olivieri y el taller.

32 AGP, Secc. Ob., Leg. 361.
} 

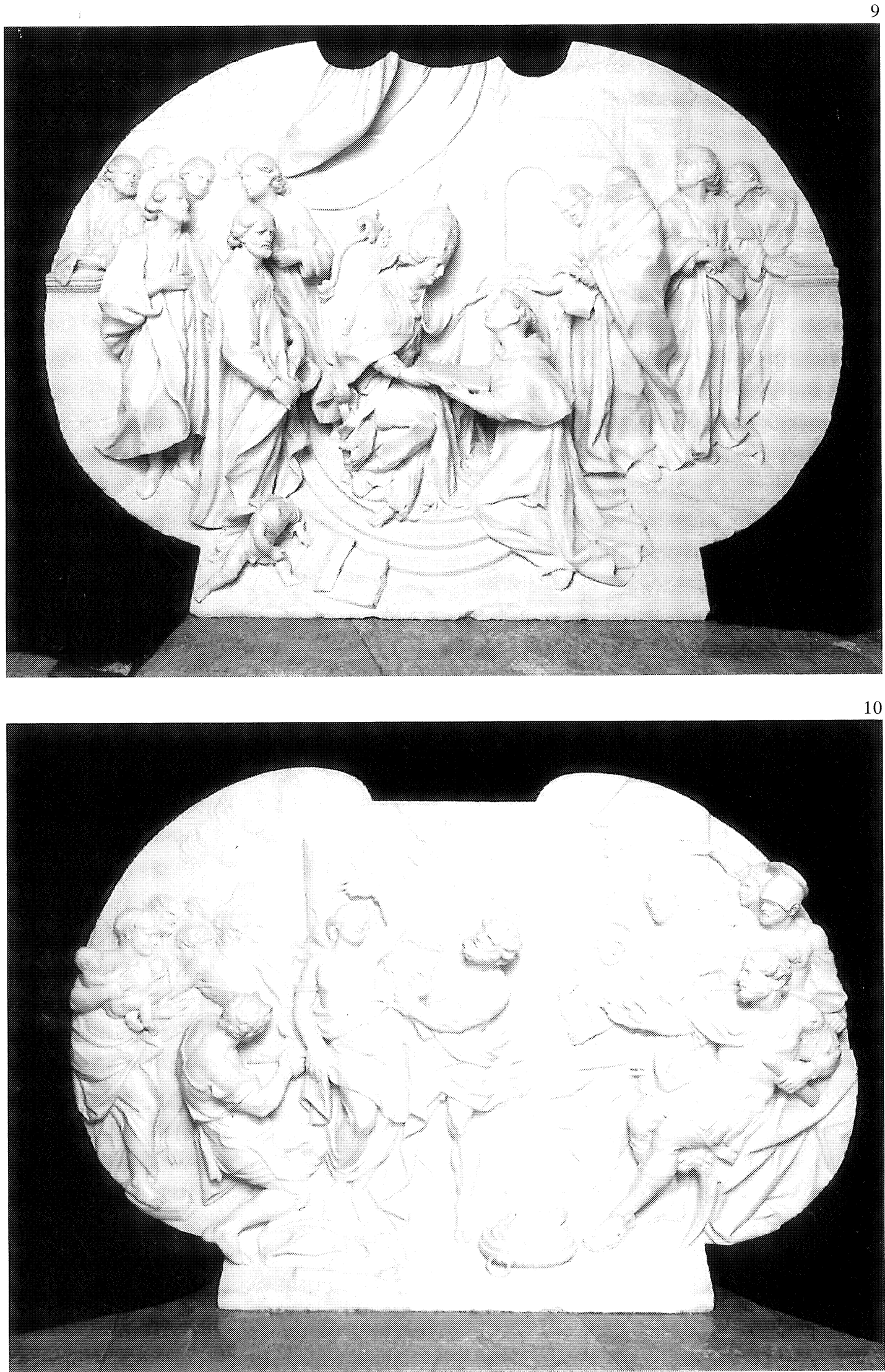

Fig. 9. Luis Salvador Carmona y Giovan Domenico Olivieri, San Dámaso y San Jerónimo. Madrid. Museo del Prado. Fig. 10. Roberto Michel, El martirio de Santa Eulalia. Madrid. Museo del Prado. 
por las regulaciones hechas y juntamente también la líquida cantidad que se le abonó, por dicho trabajo hecho en la Medalla, y por tanto a V.S. SSpco se sirva darme su recomendación para que en la Thesorería o Contaduría me den dcha certificación es merced que espero...» Al margen se dice: «Désele a esta parte la certificación que pide por la Contaduría...», rubrica esta nota Baltasar de Elgueta 33.

No era esta la única vez que encontramos a Juan de León compartiendo sus obras con otros escultores. Quizá, en este caso se justifique porque, al conocerse la decisión de eliminar los relieves que ya estaban repartidos, y tener noticia de que se les pagaría en razón del trabajo que los mismos presentasen, algunos escultores trataron de adelantarlos al máximo. Así lo explicaba Alfonso de Grana. Con toda seguridad, como el escultor aragonés estaba entonces demasiado ocupado en el sepulcro de la reina Bárbara de Braganza, no dudaría en recurrir a un compañero de profesión para encomendarle que avanzase la ejecución de la medalla antes de entregarla y así poder sacar mejor beneficio económico de este encargo, para el que tuvo que elaborar previamente el modelo correspondiente, lo cual les había supuesto, cuando menos, horas de trabajo que, muy difícilmente, podrían verse suficientemente recompensadas al eliminarse tal decoración.

Con respecto a la identificación de este nuevo escultor, Francisco Matías del Otero, sólo he logrado averiguar que había ganado el primer premio de la segunda clase de la Academia de S. Fernando en el año $1757^{34}$.

Prosiguiendo con la autoría de los relieves se nos plantea una nueva cuestión: ¿quién es, realmente, el autor de algunas de estas medallas que se entregaron apenas desbastadas y hoy los contemplamos acabadas? Se ha venido aceptando, sin ningún género de dudas, como autores a aquellos escultores a quienes se les había adjudicado su realización, pero el hecho no se puede admitir como regla general. En razón de la estimación o valoración que Juan Pascual de Mena y Roberto Michel dan a los doce relieves recogidos, y utilizando como punto de referencia la valoración que se da a aquellos que, como los de Olivieri, nunca se llegaron a terminar, además de la ayuda que nos facilita el archivo del Palacio, podemos llegar a conclusiones al respecto. Esta cuestión únicamente afecta a los últimos doce entregados y eran: «una Medalla de Sn. Isidro y Santa María de la Cabeza, concluida, con el Modelo del propio tamaño executada por Luis Salvador Carmona... Otra del mismo que representa $S n$. Dámaso y Sn. Gerónimo, con otros adornos y figuras a medio desbaste, con el Modelo hecho del propio tamaño, vale... 5.000 rs. Otra que representa la Ruina de Numancia, de D. Antonio Moyano, casi acabada, que con el Modelo y mérito vale... 15.000. Otra Medalla que representa la Ruina de Sagunto, muy adelantada, de Dn. Juan de Villanueva... 10.500. Otra.. de la Toma de Granada a medio desbaste, y modelo del propio asunto, de Dn. Juan Domingo Olivieri vale... 2.500. Otra en el mismo grado que la antecedente, que representa la Toma de $\mathrm{Me}$ xico, del mismo... 2.500. Otra Medalla que representa la Teología Divina, concluida... de D. Juan de Barrionuevo, vale 15.000 Otra.. empezada a desbastar que representa la Medicina, de Dn. Alonso de Grana... vale 2.000. Otra.. que representa la Virgen hechando la Casulla a Sn. Ildefonso, de Monsiur Franc ${ }^{\circ}$ (que estè en Gloria), vale... 8.000. Otra... de un Concilio Toledano, bien adelanta$d a .$. de Dn. Juan de León, vale... 8.000. Una Piedra contorneada que el Modelo que se había de ejecutar representa la Biblia Regia, de Arias Montano, dedicada al Papa Gregorio XIII y al Rey Felipe II, advirtiendo que este Modelo es del propio tamaño de la piedra hecho por Bergaz y aunque no concluido tiene mérito, vale... 4.000 rs. Otra... que representa la Astrología, a medio desbaste, con la fatiga del Modelo, por Dn. Joseph Oñate vale... 3.000» 35.

33 AGP, Secc. Ob., Leg. 267.

${ }_{34} \mathrm{El}$ relieve trabajado por el escultor tenía como tema Teodomiro Obispo de Iria, y el ermitaño Pelayo alumbrados de noche de luces celestiales descubren el sepulcro de Santiago.

35 AGP, Secc. Ob. Leg. 471. 
Los tres que se dice no encontrados y que completaban los quince repartidos no es que hubiesen desaparecido, sino sencillamente, que los escultores, aunque habían hecho el modelo, no habían iniciado el trabajo en el mármol y así nos lo aclara el escultor Castro: «Se distribuyeron las Medallas de los corredores asignándoseme dos en particular que son la Batalla del Salado ganada pr el Rey Dn. Alfonso el XI, y la toma del Cuzco pr. Dn. Francisco Pizarro, dándose igualmente a mi compañero $\mathrm{Dn}$. Ju ${ }^{\circ}$ Domingo Oliviery distribuyéndose las restantes en varios Escultores, bajo de su respectiva dirección, de las cuales hay dos de las más que aún no se han concluido, y se encargaron la una a Dn. Antonio Moyano, y la otra a Dn. Manuel Bergás (Bergaz)" -no Alfonso Bergaz como se ha dicho hasta ahora-, «el cual sólo ha ejecutado el modelo, y escuadrado la piedra; pero la de Moyano se haya quasi acabada; y de las dos de mi particular repartimiento, tengo ejecutados los modelos» ${ }^{36}$. De los dos modelos hechos por Castro, el de La Batalla del Salado se conserva en la Academia de San Fernando, mientras que la Toma del Cuzco hay que darlo por desaparecido. Igual suerte ha debido correr el modelo de la Biblia Regia de Arias Montano, hecho por Manuel Bergaz, mientras que el modelo trabajado por Antonio Valeriano Moyano correspondiente a su medalla La Destrucción de Numancia (Museo del Prado), ha llegado hasta nosotros y se conserva también en la Academia.

Por mandato de Carlos III, Olivieri y Castro tenían que acabar los entregados sin terminar, teniendo en cuenta para la distribución entre ellos, bajo quién de los dos habían estado trabajado los escultores su medalla; de forma, que consta documentalmente cuáles fueron los que pasaron a casa de Olivieri y cuáles las que se entregaron a Castro. A este último sólo le correspondió La Destrucción de Numancia pero, precisamente, esta medalla estaba "cuasi acabada" y así él mismo lo confiesa en el documento anteriormente transcrito, luego hay que seguir considerando a Moyano como su autor. Los dos suyos, no iniciados y el de Bergaz, al no haberse iniciado el labrado en mármol -era una pieza de mármol sólo contorneada sin ninguna labor- no se ultimarían jamás.

A Olivieri, por el contrario, al ser el director de aquellos artífices que las habían entregado a medio labrar, le correspondieron la gran mayoría de los relieves inacabados. Hemos logrado saber con toda precisión cuáles pasaron a casa del escultor italiano para que éste los concluyese. En total fueron nueve: San Dámaso dictando a San Jerónimo «a medio desbaste», El III Concilio de Toledo, La Astronomía «a medio desbaste», La Medicina «empezada a desbastar, las dos suyas", y Nra. Sra. poniendo la casulla a San Ildefonso "sin acabar» ${ }^{37}$. La de Juan Martínez Barrionuevo no pasó, pues se dio por concluida y la de Juan de Villanueva no llegó tampoco a casa de Olivieri, por idénticas razones; pero todas las demás, con sus respectivos modelos ${ }^{38}$, fueron trasladados por orden de 8 de mayo de 1761 y depositados en el domicilio del escultor italiano el día 20 de mayo de ese mismo año. De aquí que, a la vista de las noticias de archivo que hemos transcrito y del estado en que hoy contemplamos estas piezas, surja la necesidad de replantearse ¿quiénes son los verdaderos autores de los citados relieves?

Examinándolos minuciosamente y teniendo siempre presente las tasaciones y puntualizaciones que se hacen sobre su estado de ejecución, podemos afirmar primero: que la medalla de $L a$ Medicina, del escultor Alonso de Grana que se valora a su entrega en 2.000 rs - este precio incluía el modelo- era una obra que estaba apenas esbozada y, por supuesto, menos elaborada que cualquiera de las dos de Olivieri, anteriormente citadas. Se necesitaba, pues, labrarla casi íntegramente para darla por concluida. Consecuentemente no llegó a acabarse ni por su autor, Grana, ni tampoco por Olivieri, es por tanto un relieve inexistente. Por su escaso trabajo acaba-

\footnotetext{
$36 A G P$, Secc. Ob., Leg. 471, publicado por M. L. Tárraga, op. cit., vol. II, pág. 490.

$37 A G P$, Secc. Ob., Leg. 450, publicado por M. L. Tárraga, op. cit., vol. III, pág. 908.

38 Ibidem.
} 


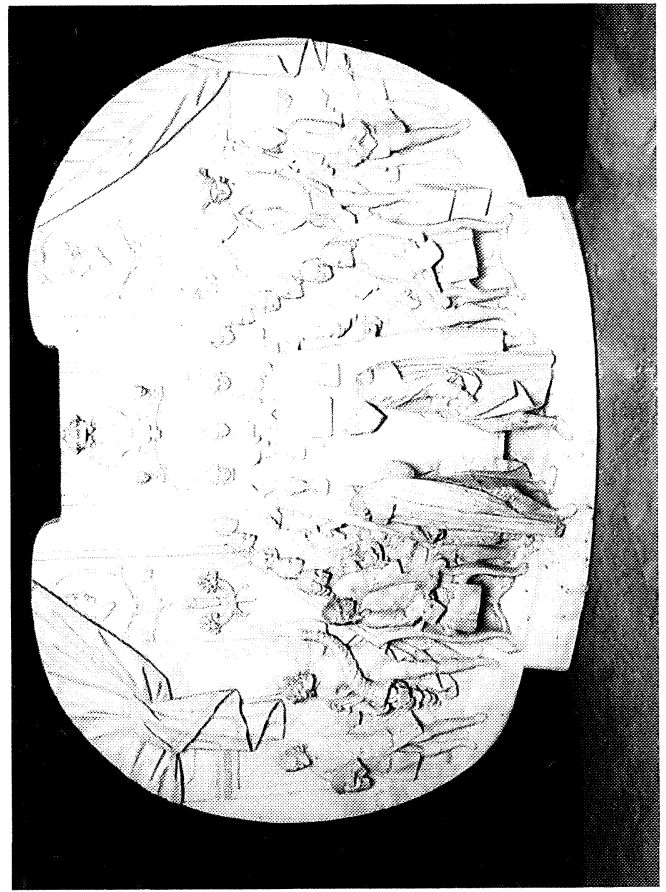

I

$\Xi$

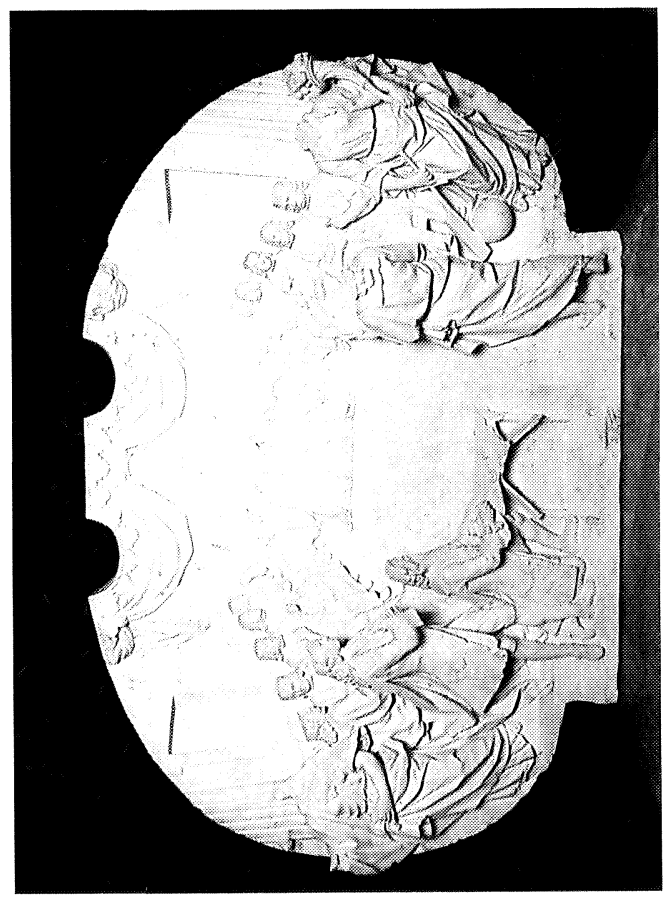

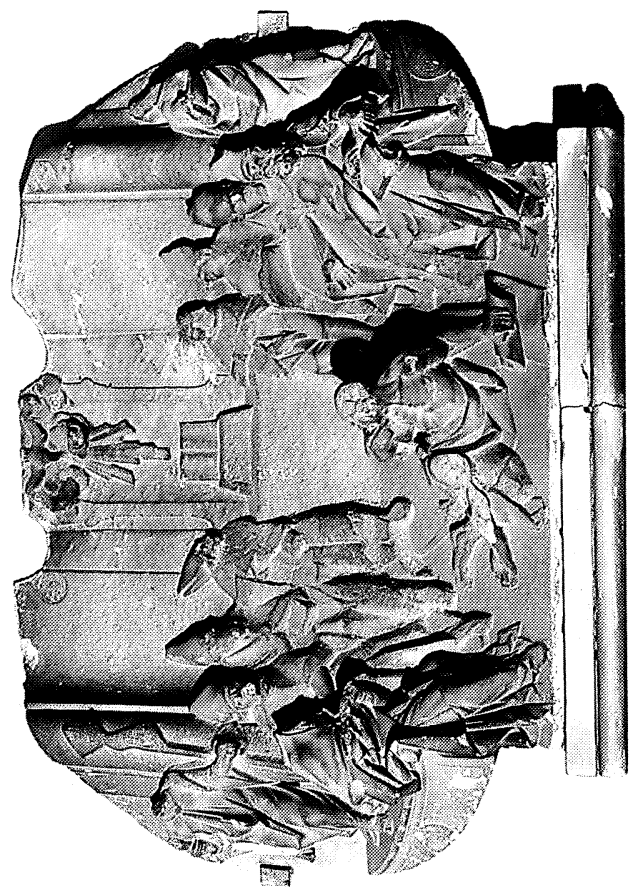

$\Xi$

$\stackrel{2}{2}$

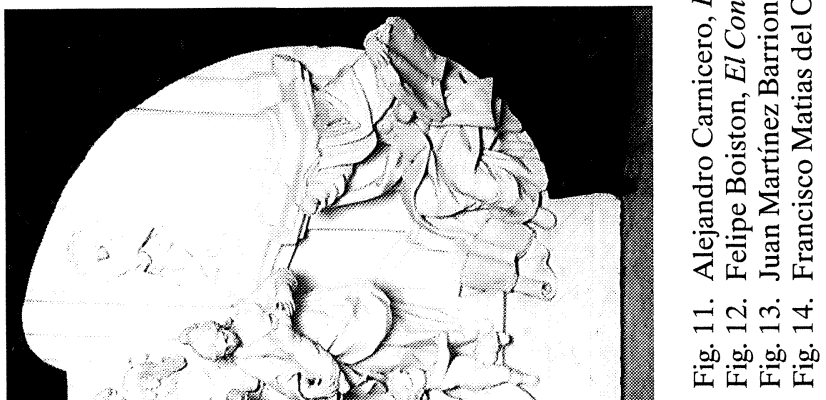


ría por despreciarse lo poco que estaba hecho y el modelo hay que darlo por desaparecido. Algo similar ocurrió con el que debía representar La Astronomía, del escultor José Oñate, apreciado en 3.000 rs. El precio adjudicado, nuevamente, nos indica que su estado de ejecución sería muy semejante a los dos conservados del carrarés, pero no figura tampoco entre los que llegaron al Museo del Prado o se trasladaron a la Academia. Es otro de los relieves que también me atrevo a asegurar no se terminó y, como únicamente estaba empezado a desbastar, se acabaría desechándolo.

El de Juan de León, o mejor Francisco Matías del Otero, quedó en el estado que lo entregó su autor y así permanece actualmente en el Prado.

Pero el hecho más curioso nos lo plantean los otros dos relieves que también se llevaron a casa de Olivieri: uno el de San Dámaso y San Jerónimo, entregado por Luis Salvador Carmona y sólo tasado en 5.000 rs, suma que refleja, una vez más, que lo labrado era muy escaso, aparte que se precisa está «a medio desbaste». El otro, La imposición de la casulla a San Ildefonso, bastante más elaborado, puesto que se valoró en 8.000 rs. El autor de este último, Francisco Devoge, ya había fallecido cuando la obra se le entrega a Olivieri. Una vez más, las valoraciones ayudan a intuir el estado en que se encontraban y cuánto podía faltar para su conclusión en una y otra medalla, aparte de disponer de otros relieves como punto de referencia: los dos del italiano, ya citados, que también se dice están "a medio desbaste» como el de Carmona y El III Concilio de Tole$d o$, que fue tasado en una cantidad similar a La imposición de la casulla a San Ildefonso.

A la vista, pues, de todos estos datos y de la información documental habría que concluir que la medalla de San Dámaso entregando la Biblia a San Jerónimo (fig. 9) no es exclusivamente obra de Luis Salvador Carmona, sino comenzada a desbastar por éste y acabada por Giovan Domenico Olivieri. El grado de participación de uno y otro lo deducimos teniendo en cuenta el estado en que se le entrega a Olivieri y el aspecto que hoy nos ofrece. García Gainza ${ }^{39}$ reparó en que esta obra de Carmona se recogió sólo desbastada, razón que le lleva a pensar, lógicamente, que «la labor del escultor aún no había concluido». Sobre este relieve, Lorente Junquera que, curiosamente, no le dedicó ninguna atención en su estudio ya varias veces citado, sí lo analiza en el Catálogo de la Escultura del Museo del Prado ${ }^{40}$ y aparte de describir la escena en él representada y darlo como obra de Luis Salvador Carmona, añade: «Son admirables las calidades de los ropajes y la vitalidad de los rostros." Sin pretender desmerecer el arte de Carmona, podemos, partiendo de los datos conocidos sobre esta pieza, observar en ella y no sólo en el grupo principal de San Dámaso y San Jerónimo, sino también en el de los discípulos a la izquierda del Pontífice (fig. 9) varias características que delatarían esa intervención del estatutario de Carrara por la forma de estar trabajado el mármol: detallismo, gusto por horadar el iris de los ojos en todos sus personajes, apreciable en todos los rostros representados, aun aquellos más alejados de los dos principales protagonistas; el acabado a base de conseguir superficies muy pulidas e incluso apreciamos que algunas de las manos muestran cierto alargamiento. Estas características y otras como la realización de los trajes y plegado de los paños, parecen ser signos elocuentes de esa intervención, en su acabado, del escultor italiano. En este caso se está cumpliendo lo que Castro trataba de evitar con su escrito de protesta a la Junta y con su negativa a concluir trabajos de otros y es que se produjese confusión sobre quién era el autor y la necesidad de que cada obra tuviese autor conocido. La participación de Olivieri, sin embargo, puede plantear también algunas dudas, porque, aunque con toda seguridad el relieve de Carmona se le entregó en su casa y una orden real le obligaba a su conclusión, bajo amenaza económica, lo cierto es que Olivieri sólo dispuso de aproximadamente mes y medio para poder obedecer la orden del Rey en este

39 García Gainza, M. C.: El escultor Luis Salvador Carmona, Servicio de Publicaciones de la Universidad de Navarra, S. A., pág. 50 .

40 Blanco, A., y Lorente, M., op. cit., pág. 232. 
sentido. La proximidad de su enfermedad y su ausencia de la Corte a primeros de julio de 1761 le impedirían cumplir por completo el mandato real. Quizá, por esa escasez de tiempo sólo pudo terminar el de Carmona y La imposición de la casulla a San Ildefonso, de Francisco Devoge. En este último caso la labor estaba más avanzada. Devoge había fallecido cuando se le encarga al artista italiano que lo acabe. El relieve es de los que hoy guarda el Museo del Prado. Como esta pieza estaba más elaborada, la intervención del carrarés sería menor. Por otra parte parece lógico pensar que Olivieri comenzase por terminar de labrar su propia obra pero, sorprendentemente, son los únicos que sabemos se trasladaron posteriormente a casa de Castro.

La enfermedad de Olivieri y su desplazamiento a Valencia, teniendo que abandonar Madrid y consecuentemente su casa y taller, justificaría el por qué ni el de Grana, ni el de Oñate ni el de Francisco Matías Otero, e incluso ni los dos suyos los terminó. Es decir, sólo tendría tiempo material de concluir el desbastado por Carmona y el de Francisco Devoge. Tras su muerte, dos de ellos, el de Oñate y Grana, se despreciarían por su incipiente trabajo, mientras nos encontramos que únicamente se ordenaba el 29 de marzo de 1762 el traslado a casa del escultor Felipe de Castro, precisamente, de las dos medallas del escultor principal, con sus modelos correspondientes. El hecho de querer conservar ambas medallas, a pesar de estar sólo esbozadas, sin duda, hay que justificarlo en el reconocimiento que gozaban las obras del artista italiano. Castro, que tan reacio se había mostrado a ultimar trabajos de otros escultores, fue respetuoso y consecuente con sus principios a la hora de cumplir con las órdenes de Carlos III, que le obligaban, en este caso, a terminar un relieve de su compañero y contrincante en la dirección del taller real. Iría dando largas al asunto y a las preguntas, que consta se le hicieron, sobre el estado o adelantamiento en que tenía este trabajo, respondería con evasivas y amparándose en que otros encargos más urgentes le obligaban a postergar esta obligación. Al morir Castro, volvieron en su estado original, nuevamente, a los almacenes reales y así pasaron, años después, al Museo del Prado ${ }^{41}$.

También hay que precisar en este mismo sentido que El Consejo de Ordenes, en depósito en la Real Academia, no es exclusivamente obra de Alejandro Carnicero, sino trabajo conjunto de él y su hijo Isidro. Así lo atestiguan varias noticias de archivo. Concretamente, la valoración que de él hizo Felipe de Castro, fechada el 23 de marzo de 1757, quien dice textualmente: «... Pasé a reconocer al Almacen de palacio, la Medalla del Consejo de Ordenes que se repartió al difunto Alexandro Carnizero, y ha concluido, su hijo Isidro; y hallo vale su trabajo once mil y quinientos reales de vellón...» ${ }^{42}$. La noticia aparece recogida en otros documentos. También al pagársele a la viuda de Carnicero, Ana Santos, esta obra, se repite la noticia, pero aquí se dice: «que ejecutó dho. Alejandro y por su fallecimiento concluyeron dichos sus hijos.... 43 .

Siguiendo precisando los autores, es obligado detenernos en la medalla que representa la Gramática (fig. 6) obra de Gregorio Carnicero. Castro, al enjuiciarla, puso en duda quién era su verdadero autor. Este detalle y la dureza con que la analiza merece que reproduzcamos el texto, inédito hasta ahora, del escultor gallego, que nos sirve para conocer su juicio sobre esta obra, pero también nos descubren la personalidad, formación y erudición del propio Castro, quien dice: «Certifico que por orden del S ${ }^{\circ}$ Dn. Balthasar Elgueta, y Vigil... pasé al Almacen al reconocimiento, y tasa de la Medalla en mármol de Badajoz se me dice ha ejecutado Dn. Gregorio Carnicero, la que representa el Arte de la Gramática; y teniendo presente una orden del S ${ }^{\circ} \mathrm{r}$ Intendente de 4 de abril del año pasado de 1757 en la que me hace entender que S. M. le manda prevenga

\footnotetext{
41 Manuel Lorente los catalogó con los n. ${ }^{\text {s }} 479$ y 481, designando al primero de ellos como La rendición de Jaén?, que corresponde a La Toma de Granada y el segundo como Batalla ante una ciudad fortificada y cuyo verdadero motivo es La Conquista de Méjico.

42 AGP, Secc. Ob., Leg. 4.

43 AGP, Secc. Ob., Leg. 385.
} 
que siempre que se me presente alguna obra para tasarla, la aprecie según el trabajo, y acierto con que está executada: por tanto obedeciendo... digo que en esta Medalla se hallan muchas cosas buenas: es a saber, buena composición, buenas actitudes y partido de Paños en algunas de las figuras y todo bien lustrado; pero al mismo tiempo se hallan muchos desaciertos como son el que la mujer que representa la Gramática (que es el Héroe que llamamos de la Historia) está mal dispuesta asi en actitudes como en paños corrompiendo estos y dislocando el desnudo de la figura, que debía de hallarse debajo de ellos; su rostro es de caracter mezquino, los brazos y demás miembros son toscos o grosolanos cuyo carácter se observa más bien en los dos niños que están a cada uno de los lados de la Gramática, que son de los más malos que se puede hacer, asi en rostro como en disposición y corrompido de desnudo; la perspectiva está mal entendida porque el punto de vista está en alto en medio de la historia, y los planos y Arquitectura no están sujetos a este punto encaminándose a otros varios, que es contra la naturaleza de el que mira una acción y objeto; la figura que está a la izquierda de la Gramática en primer término que quiere representar a nuestro Insigne Antonio de Lebrixa pero no lo consigue, por parecer un flamenco con la gorguera de lechuguilla que tiene en el cuello y en las manos cuyo traje no se usó en el siglo xv que es en el que floreció este nuestro famosísimo literato, ni la fisonomía es la suya; el retrato de Antonio de Lebrixa lo tenemos en su Diccionario Latino y español que se imprimió en Granada el año de 1536 abierto de buril por Phelipe de Borgoña que lo copió del que poco tiempo antes había pintado por el natural, Rincón Pintor de los Señores Reyes Católicos Dn. Fernando y $\mathrm{D}^{\mathrm{a}}$ Isabel, como largamente explican los versos que se leen debaxo de este retrato en dcho Diccionario. Allí se ve su rostro muy semejante al de Aristóteles (como nos lo describe Dn. Antonio en su Biblioteca) y su vestido semejante al del rey Fernando el Católico; con el cuello descubierto y de edad crecida que muestra acercarse a los 77 años al fin de los cuales murió en el de 1522. Todo lo cual debía indagar el que esculpió la medalla para no cometer errores semejantes; porque los Artífices es necesario que sean eruditos, y introducidos en las Ciencias, que sepan bien las fábulas, las historias, los tiempos, y los ritos para que sus obras las executen con acierto, y se distingan de las mecánicas y mercenarias. En atención pues a la desigualdad de este bajo relieve de la Gramática vengo en conocimiento que son varios los autores de él: que las mejores figuras son tomadas de las estampas de Rafael y de otros maestros: las figuras malas son de un autor moderno; la perspectiva y Arquitectura es de otro; y la ejecución de otros; de que se sigue que Dn. Gregorio Carnicero no es el autor, ni de la composición, ni execución de dcha Medalla, sino un mero operario que ayudó a trabajarla. Todo lo cual soy pronto a demostrar con más evidencia presente a la obra y al que suena haberla hecho, por cuyos motivos y respecto a todo lo dicho hallo que vale esta Medalla de la Gramática, doce mil reales de vellón. Madrid y Enero 14 de $1758 " 44$.

Curiosamente, en el transcurso de las investigaciones sobre esta decoración escultórica, he podido comprobar que cinco de las medallas que conserva el Museo del Prado están firmadas en el lateral, aprovechando el espacio grueso de la pieza de mármol. Exactamente son: las de Carlos Salas, Andrés de los Helgueros, Juan Martínez Reina, Fernando Ortiz y Gregorio Carnicero (figs. 16, 17, 18, 19 y 20). Esta última es, precisamente, la que Castro asegura no es obra del citado escultor. Ignoramos, las razones que tuvo para poner en tela de juicio la intervención de Gregorio Carnicero en el relieve de la Gramática, aparte de las que alega en su escrito y que se basan en los desajustes históricos de: indumentaria, fisonomía del retratado y otras imperfecciones de su ejecución, errores que con tanta frecuencia cometían los mejores escultores del XVIII en sus obras. Cabe preguntarse, ante la opinión de Castro, si tal vez Gregorio Carnicero era tan excelente escultor y tan erudito como para que se esgrimiera como argumento de peso para re-

44 AGP, Secc. Ob., Leg. 460. 


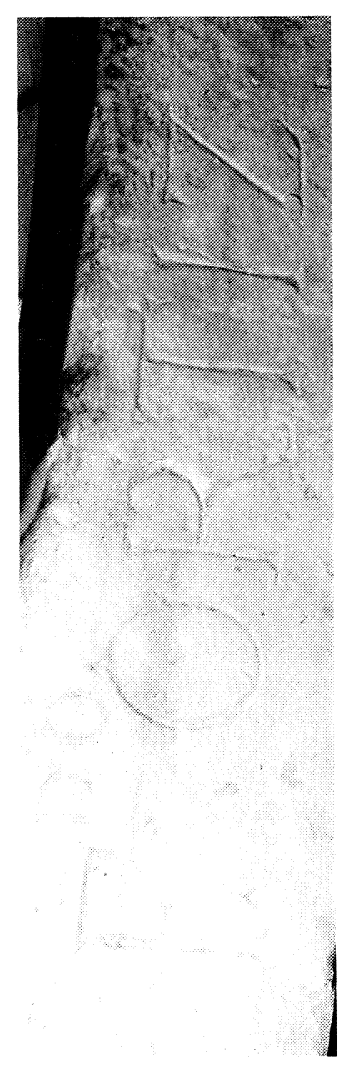

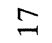

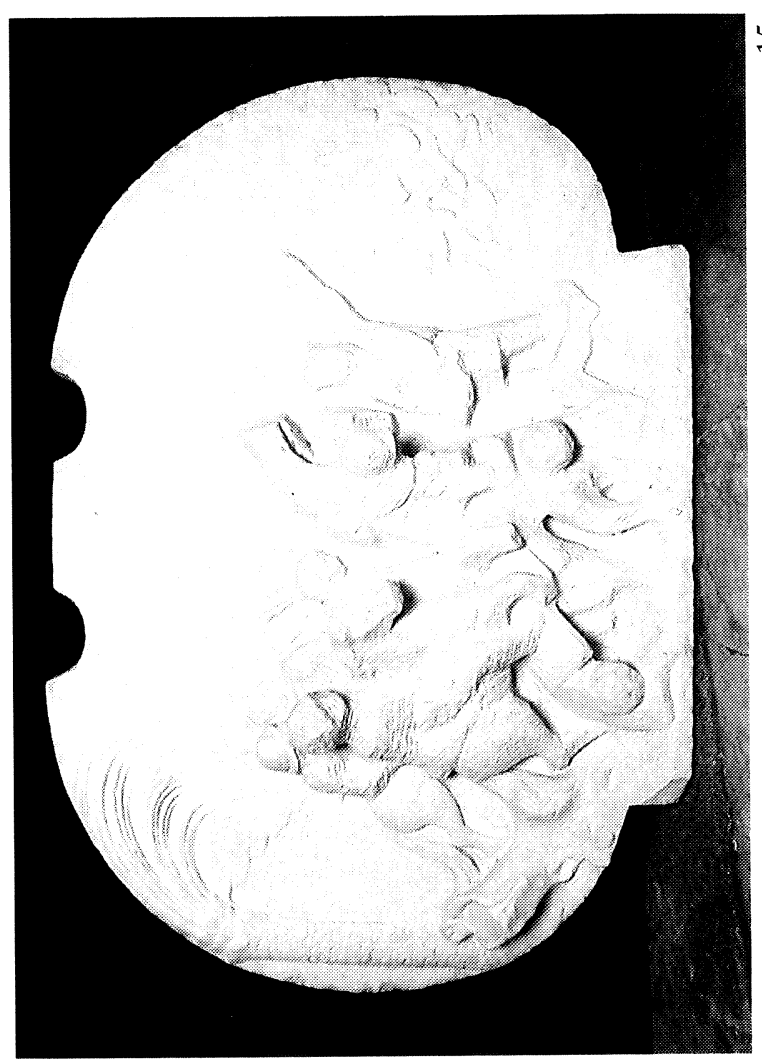

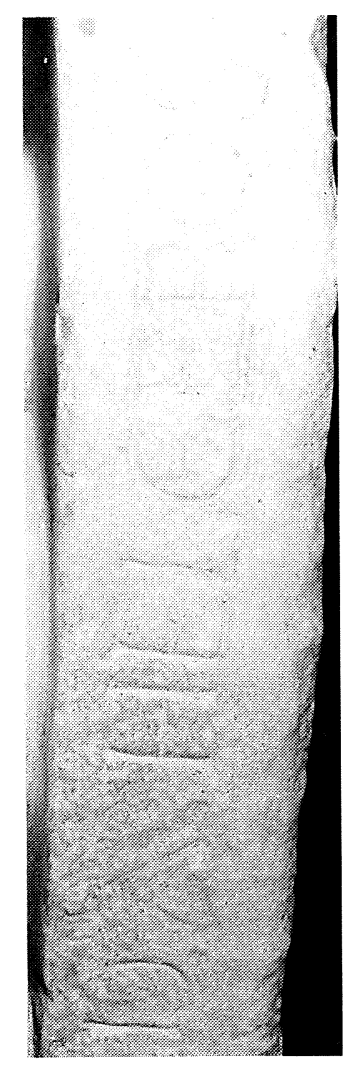

$\stackrel{\infty}{\sim}$

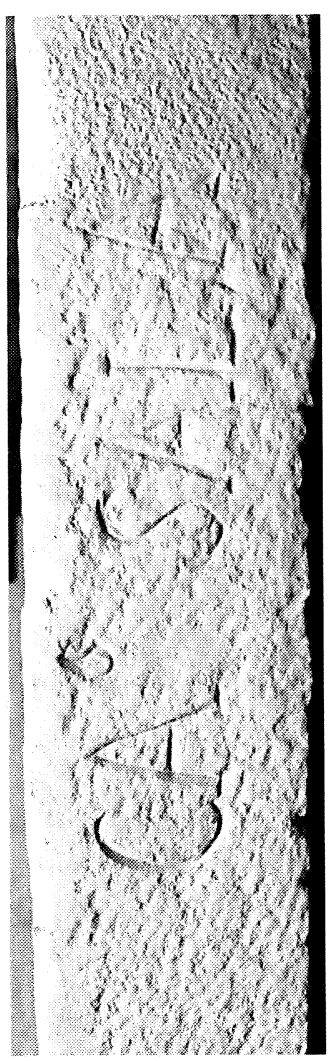

2

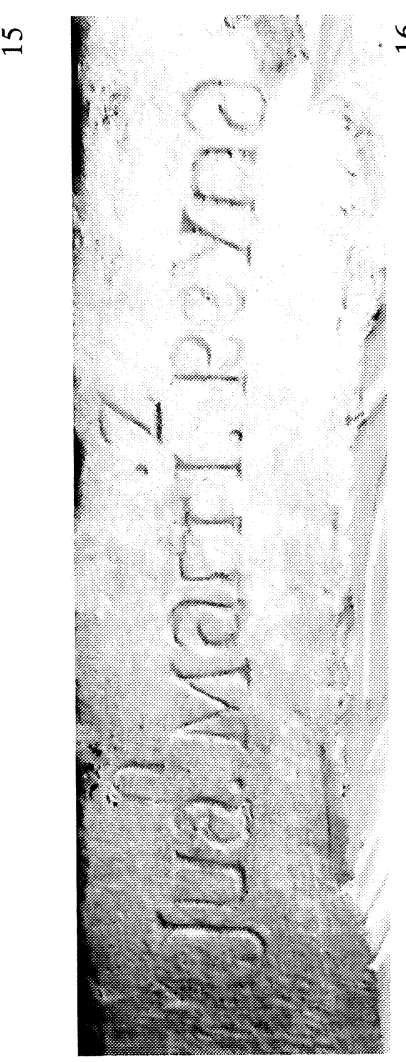

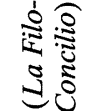

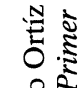

롤

造带

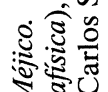

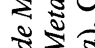

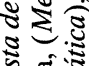

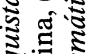

केष

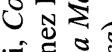

逜:

穷

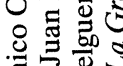

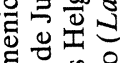

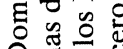

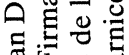

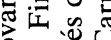

iे

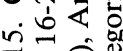

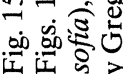


chazar este relieve como obra suya, la falta de rigor en la escena labrada o ¿quizá tendría Castro razones que afectasen más directamente a su relación con la familia de los Carnicero? Opino que es un ejemplo más de su orgullo personal y profesional, suscitado en esta ocasión a raíz de la disparidad de criterios entre Castro y Olivieri al enjuiciar la medalla el Consejo de Ordenes hecha por otro miembro de la familia Carnicero, Alejandro, que obligó, no sólo a retasarla por parte de Carmona, Michel y Mena, sino que les valió a ambos escultores el que, a través del conde de Valdeparaíso, se les advirtiese que cuando hiciesen sus tasaciones y valoraciones procurasen «... no se perjudique a la real Hacienda ni tampoco a los Profesores que ejecutan las obras.... y manda S. M. «las aprecien según el trabajo, y acierto con que este executada, sin hacer comparaciones con los precios, a que se hubieren pagado las obras antecedentes por que lo contrario, sobre ser muy irregular, entiende S. M. que puede ocasionar graves perjuicios.... ${ }^{45}$.

Creemos hallar en esta reprimenda real la verdadera causa de tan minucioso análisis del relieve de Gregorio Carnicero. Si bien he tratado de localizar la edición del Diccionario latino-español citado por Castro y en el que aconsejaba debió de haber buscado su inspiración el mencionado escultor, no ha sido posible efectuar tal consulta, pues las ediciones halladas no se corresponden con la cita del escultor y ningún grabado aparece en otras ediciones localizadas que reproduzcan la imagen a que alude el artista gallego.

Olivieri, al enjuiciar esta misma obra, opinaba: «... Este Artífice no ha aorado tiempo ni fatiga para esmerarse y azer quanto ha savido, tanto en la Composición del todo, como en su Conclusión, no deja de tener defectos, pero son tolerables y los disimulerá la distancia, por lo que según mi inteligencia allo que vale la obra de manos quatorze mil Rs. vn, por las muchas figuras que tiene, y trabajo, esto es mi dictamen que sujeto al de V. S.... ${ }^{46}$.

Es cierto que en la mayoría de sus juicios o valoraciones Olivieri siempre trata de disculpar cuantas imperfecciones puedan presentar las obras, buscando apoyarse más en aquellos aspectos positivos que muestran las piezas labradas, o en reconocer el trabajo que presenta o en el esmero o interés que puso el artista, buscando siempre justificar al escultor y confiando en la distancia de su contemplación como el remedio a los posibles defectos. También apuntamos que la suavidad al enjuiciar este tipo de trabajo radicaba en que los conocimientos de nuestra Historia eran, sin duda, inferiores a los que poseía Castro.

El hecho de haber hallado estas cinco medallas firmadas permite, a su vez, rectificar la atribución hasta ahora equivocada sobre los autores de dos de estos relieves: el que se ha venido considerando obra del escultor malagueño Fernando Ortiz, cuyo verdadero autor es Martínez Reina y que representa La Metafísica y la Dialéctica -no la "Física y Metafísica»- y el relieve hasta ahora considerado obra de Martínez Reina, cuyo verdadero autor es Fernando Ortiz y que representa La Filosofía. Uno y otro están firmados en su borde lateral (figs. 7 y 8). La afinidad entre las Ciencias a representar, Filosofía y Metafísica, e incluso los motivos elegidos y labrados en ellos como imagen de ambas, han propiciado tal confusión. Martínez Reina desplaza a los personajes femeninos que dan título a la obra hacia ambos extremos del relieve. Elige como centro de la escena una palmera, árbol cosmogónico y antropogónico que simboliza entre otras cosas la riqueza y la generación y apunto como posible interpretación el que en su tronco, como tronco de la Filosofía, inscribe en seis círculos seis letras: S, C, V, A, H, y en el último de ellos SOC. A este tronco aparece abrazado la figura de Platón, personificación de la Filosofía como Ciencia Universal, quien situado en esta forma parece recoger la herencia no sólo de su maestro Sócrates, sino de algunos otros filósofos que le precedieron y, según esta hipótesis, las referidas letras deben corresponder a iniciales de filósofos famosos que le precedieron: ¿Solón?, ¿Anaxágoras?, ¿Ze-

\footnotetext{
45 AGP, Secc. Ob., Leg. 456.

46 AGP, Secc. Ob., Leg. 460.
} 
nón? (Cenón), ¿Heráclito?, la U o V que no alcanzo a identificar por ahora y, por último, su maestro Sócrates. Si con el brazo izquierdo abraza el tronco de la Filosofía griega, y con la derecha mantiene un manuscrito, su rostro parece dirigirse hacia la figura que descabezada representaría a su discípulo Aristóteles. Platón está sentado sobre un plinto que reproduce símbolos pitagóricos, mientras Aristóteles apoya su mano sobre un disco o reloj solar. Al otro lado creemos está personificado su condiscípulo Euclides. Otra serie de símbolos matemáticos deben aludir, sin duda, a su relación con los filósofos pitagóricos. La Dialéctica aparece sentada a la derecha con llaves y espada de doble filo en sus manos y armada de casco a modo de una Minerva, mientras la bella figura de la izquierda personifica a la Metafísica, según propone Cesare Ripa para su representación ${ }^{47}$ : mujer con un Globo y un reloj a los pies, los ojos vendados y una corona en la cabeza, haciendo un gesto de contemplación y en la izquierda un cetro, porque siendo la reina de todas las Ciencias adquiridas por luz natural y expresando las cosas sujetas a mutaciones y al tiempo, considera las cosas superiores con la sola fuerza del intelecto, no preocupándose de los sentidos.

La otra medalla de La Filosofía, obra firmada de Fernando Ortiz, fue concluida por el escultor malagueño en octubre de $1756{ }^{48}$ y su modelo consta lo presentó a la Academia a fin de conseguir algún distintivo para, según refiere, "volver a su Patria con este honor» ${ }^{49}$. El modelo de este relieve le valió el nombramiento de Académico de Mérito por la escultura, honor que agradecía el artífice en un escrito fechado el 22 de octubre de ese mismo año dirigido a D. Ignacio de Hermosilla ${ }^{50}$. La adjudicación de esta obra le fue otorgada por el Intendente del palacio como reconocimiento o premio a la labor que venía desempeñando como encargado de la saca de jaspes y mármoles en las canteras de Andalucía. El propio Elgueta elogia no sólo su conocida habilidad, la que dice le consta "por una Medalla de mármol que trabajó aquí para el Corredor, que no hay otra igual en el Almacén, en el sentir de los inteligentes». Añadía a ello sus virtudes humanas: «... busqué a este hombre por su hombría de bien, Christiandad, y inteligencia para este encargo...." ${ }^{51}$.

Siguiendo la idea del P. Sarmiento, Ortiz representó a la Filosofía personificada en figura de mujer joven y bella que en la mano derecha sostiene algunos libros cerrados y en la izquierda un cetro real y aquí se acompaña entre Teofrasto y Plinio.

La firmada por Andrés de los Helgueros (fig. 18), el oficial y yerno de Juan de Villanueva (padre), sigue también la iconografía propuesta en la obra de Ripa para representar las Matemáticas, con desigual acierto en su ejecución ${ }^{52}$. Para Olivieri, Helgueros había hecho todo lo que había sabido. Según él «pudo enmendar algunos defectos que le advertí algunas veces y no lo hizo como debía, aunque se puede disimular por la distancia, y considerando el mucho trabajo que tiene y el número de figuras, lo bien bruñida y concluida que está, el tiempo que habrá consumido.... ${ }^{53}$. La observación minuciosa de esta pieza refleja el influjo de los modelos de Olivieri con quien el escultor venía trabajando desde los primeros años de crearse el taller real de escultura. Concretamente, el tocado de la mujer que personifica la Matemática reproduce el de Santa Bárbara en el altar mayor de las Salesas, aparte de algunos otros detalles, tales como el plegado de algunos trajes.

47 Ripa, C.: Iconología, pág. 327.

48 AGP, Secc. Ob., Leg. 4.

49 A. Academia de San Fernando, Leg. 42, Arm. 1.

50 Ibidem.

51 AGP, Secc. Ob., Leg. 456.

52 Pueden hallarse otras noticias referidas a este escultor en M. L. Tárraga: «La fachada de San Cayetano de Madrid: Juan de Villanueva y Andrés de los Helgueros", Rev. AEA.t. LIX, n. ${ }^{\circ} 236,1986$

53 AGP, Secc. Ob., Leg. 382. 
Por último, otro de los firmados corresponde a Carlos Salas: El Primer Concilio de España (fig. 19). Salas, que entonces era discípulo de la Academia de San Fernando, y había sido premiado por esta institución en la primera y segunda clase de escultura, pedía trabajar una de estas medallas, alegando en su súplica, aparte de sus méritos, el que «en inteligencia del Suplicante no reconoce (en los que la ejecutan), Superioridad alguna...». Sugería que se consultase a la Academia su mérito, así como al Viceprotector de la misma, y se ofrecía a realizar el modelo del relieve que se le adjudicase y, una vez trabajado, someterlo al parecer y aprobación de la Academia. De rechazársele no pediría ni insistiría en ello ${ }^{54}$.

Carlos Salas consiguió labrar dos de estas medallas, pero compartiendo el trabajo con Manuel Bergaz: La Batalla de las Navas, Museo del Prado (fig. 2) y D. Pelayo o La Batalla de Covadonga, Museo del Prado (fig. 1), pero casi sin haber llegado a terminar la de Las Navas de Tolosa, suplicaba de nuevo el poder labrar una por sí solo, apoyándose en que Manuel Bergaz lo había conseguido. Para tomar una decisión al respecto se consultó a Olivieri, al igual que se había hecho con otras muchas peticiones en este sentido: la de Andrés Beltrán, Primo, Porzel, Mateo Medina, Devoge (hijo), etc. Olivieri respondió en esta ocasión: «bien puede repartir otra medalla para que la ejecuten D. Manuel Bergaz y D. Carlos Salas que desempeñarán su obligación.... 55 . Conseguía así la adjudicación de la Batalla de Covadonga, pero la hubo de labrar conjuntamente con Bergaz, como la anterior. Finalmente, Carlos Salas logró el 6 de marzo de 1758 que se le encargase el Primer Concilio de España para «el hueco y nicho de entrada a la Capilla a mano derecha” ${ }^{56}$, obra que había concluido en febrero de 1759 y que fue tasada con una de las cantidades más elevadas de esta serie: 20.000 rs por Castro, 19.000 Olivieri, lo cual suponía el reconocimiento a un buen trabajo.

En contraste, La Batalla de las Navas de Tolosa que labró en colaboración con Manuel Bergaz fue severamente juzgada por el escultor gallego, quien el 27 de noviembre de 1757 opinaba: «... haber observado en ella muchas desproporciones en las figuras de hombres y caballos, como asimismo poca fidelidad a la Historia para distinguir a aquella célebre victoria de todas las demás de España como distinguió...» ${ }^{57}$. También de ambos autores, la medalla citada como $E l ~ I n-$ fante D. Pelayo, o Batalla de Covadonga, Castro la valoró en 9.000 rs sin ningún comentario, mientras Olivieri informó en dos ocasiones sobre ella y, una vez más, disculpaba a los artífices apoyándose en la mala calidad del mármol. Así decía Olivieri: «... las partes cada una de por sí pudieran ser mejor estudiadas, corregidas y concluidas, si la calidad de la piedra se le hubiere permitido, pues está llena de esmeriles que hacen burla de los cinceles, y no les deja perfeccionar, ni concluir la obra, como en un mármol regular lo que no deja de costar muchas más fatiga al Artífice, sin poder lograr el correspondiente lucimiento y valor de la obra, pero como va a bastante distancia de la vista, todas las imperfecciones que en ella se notan quedaran disimuladas; porque el todo de la composición y degradación es según Arte...) ${ }^{58}$. Este relieve hubo de ser retasado por Carmona, Michel y Mena.

Otros, tales como La Música obra del francés A. Demandre o La Poesía (fig. 5) de Isidro Carnicero, merecieron la aprobación de ambos Directores, sin demasiados comentarios. En el caso de La Música, Academia de San Fernando, Olivieri reconoció su buena composición, número de figuras, calados y lo bien concluida que estaba y que «el artífice se había esmerado cuanto su habilidad le había permitido y que no había ahorrado nada para concluirla bien» 59 .

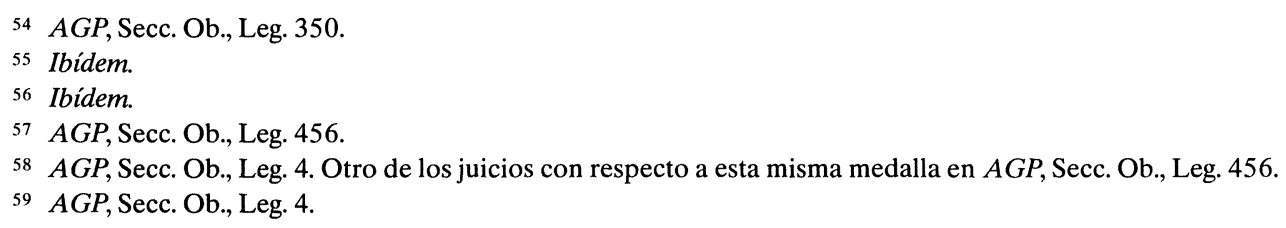


Castro será más explícito y sólo dirá: «la he visto y hallo que vale...». La medalla de La Poesía, obra de Isidro Carnicero, no sólo se consideró bien inventada, sino «bien degradada, estudiada, tanto en el todo como las partes, bien trabajada, concluida y bruñida y en fin una hermosa y bella medalla...». Así se expresaba el escultor italiano. Castro estaba de acuerdo con su compañero y consideró que estaba "bien inventada y executada". Isidro Carnicero eligió para representarla la Alegoría del Dios Apolo, las Musas y Pegaso, corcel que, aparte de transportar a las Musas, simboliza el poder de elevación y capacidad de espiritualización.

Si bien tengo previsto dedicar a estos relieves un estudio más amplio, no quiero dejar sin mencionar aquí los juicios que merecieron la labor de otros escultores que trabajaron en esta serie decorativa, concretamente, Juan Porcel a quien debemos La Batalla de Clavijo, tasada por Olivieri y Castro en 25.000 y 22.000 rs respectivamente y, según el parecer de Baltasar de Elgueta, «... no hay medalla de más obra, ni tan perfectamente acabada como esta en cuantas se han hecho" ${ }^{60}$. El mismo Intendente del Palacio, refiriéndose al Martirio de San Lorenzo, labrado por Juan de León, decía: «... este es uno de los mejores escultores y como tal ha trabajado y concluido perfectamente dicha medalla.....

No deja de ser curioso que en el caso de Roberto Michel los juicios sobre su trabajo son demasiado rutinarios y escuetos por uno y otro director, aunque Olivieri no deja de reconocer, refiriéndose a la de Santa Leocadia, que: está «bien executada y concluida, Castro, únicamente, dirá haberla reconocido y señala, escuetamente, una cantidad como valoración a su labor».

De la obra de Martínez Barrionuevo, La Teología, no ha quedado testimonio sobre su ejecución, al haberse entregado entre las doce últimas tasadas por Mena, Michel y Carmona. Estos veinticinco relieves, que actualmente conservan el Museo del Prado, se sometieron a una limpieza superficial en 1986, no habiéndose vuelto a exponer posteriormente ninguno. Esta serie ornamental que, lamentablemente, perdió la arquitectura del Palacio esperemos, al menos, poderla contemplar algún día en el Museo del Prado, pues aunque algunos hayan sufrido deterioros, fundamentalmente pérdidas de cabezas, rostros o miembros, son testimonio del gusto de un siglo, y del hacer de un amplio equipo de escultores al servicio de la Corte.

60 AGP, Secc. Ob., Legs. 460 y 4. 